\title{
Un modelo de análisis de la recepción de series de ficción: el papel de las reacciones afectivas y las creencias
}

\section{Cristina Etayo ${ }^{1}$}

Recibido: 2017-11-09

Enviado a pares: 2018-02-07
Aprobado por pares: 2018-03-09

Aceptado: 2018-04-09

DOI: 10.5294/pacla.2019.22.1.4

Para citar este artículo / to reference this article / para citar este artigo

Etayo, C. (2019). Un modelo de análisis de la recepción de series de ficción: el papel de las reacciones afectivas y las creencias. Palabra Clave 22(1), e2214. DOI: 10.5294/pacla.2019.22.1.4

\section{Resumen}

El objetivo de este trabajo ha sido indagar cuáles son las creencias de los espectadores hacia las series de televisión y las reacciones afectivas que estas provocan. Las creencias tenidas en cuenta se refieren a distintos aspectos: diálogos, tramas, actores, personajes, originalidad y variedad, complejidad, moralidad y calidad. En lo que se refiere a las reacciones afectivas hacia las series, se incluyen la cercanía cultural, la resonancia personal, la elaboración cognitiva y la actitud general. La metodología empleada ha consistido en el análisis exhaustivo de diez series de televisión, cinco españolas (Aída, Cuéntame, El internado, Águila Roja y Física o Química) y cinco norteamericanas (CSI, Friends, House, Mujeres desesperadas y Perdidos) mediante la información procedente de una encuesta telefónica realizada a 1000 personas. Los resultados indican que las creencias influyen en la calidad percibida. Los aspectos más relevantes son los diálogos, las tramas, los actores y los personajes. En relación con las reacciones afectivas, los tres elementos considerados (cercanía cultural, resonancia personal y

1 orcid.org/0000-0002-8464-0691. Universidad de Navarra, España. cetayo@unav.es 
elaboración cognitiva) apenas están relacionados con la actitud general o preferencia por la serie. Las conclusiones ponen de manifiesto que la calidad percibida viene determinada por la combinación de los diferentes factores considerados y que no existe una única configuración que dé lugar a una percepción positiva de la calidad. La contribución original del artículo a la literatura radica en la presentación y aplicación de un modelo teórico que permite determinar con detalle las creencias y actitudes de los telespectadores hacia las series de ficción televisiva.

\section{Palabras clave (fuente: tesauro de la Unesco)}

Televisión; ficción; creencias; reacción del público; reacción emocional; series norteamericanas; series españolas. 


\section{A Model Analysis of Fictional TV Series Reception: The Role of Affective Reactions and Beliefs}

\section{Abstract}

The aim of this paper has been to inquire into what viewers' beliefs are towards television shows and the affective reactions they elicit. The beliefs considered refer to aspects such as dialogs, plots, actors, characters, originality and variety, complexity, morality and quality. Regarding affective reactions towards TV series, they include cultural closeness, personal resonance, cognitive elaboration and general attitude. The method used consisted in the exhaustive analysis of ten television shows, five Spanish (Aída, Cuéntame, El internado, Águila Roja and Física o Química) and five North American (CSI, Friends, House, Desperate Housewives and Lost) using information from a telephone survey of 1,000 people. Results indicate that beliefs influence perceived quality. The most relevant aspects are dialogs, plots, actors and characters. In relation to affective reactions, the three elements considered (cultural closeness, personal resonance and cognitive elaboration) are hardly related to the general attitude towards or preference for the TV series. Conclusions show that perceived quality is determined by the combination of the various factors considered and that there is no single configuration that gives rise to a positive perception of quality. The article's original contribution to the literature lies in the presentation and application of a theoretical model that allows to determine in detail the beliefs and attitudes of viewers towards fictional television shows.

\section{Keywords (source: Unesco Thesaurus)}

Television; fiction; belief; audience reaction; emotional reaction; North American series; Spanish series. 


\section{Um modelo de análise da recepção de séries de ficção: o papel das reações afetivas e crenças}

\section{Resumo}

O objetivo deste trabalho foi indagar quais são as crenças dos espectadores em relação às séries de televisão e às reações afetivas que elas provocam. As crenças consideradas se referem a diferentes aspectos: diálogos, tramas, atores, personagens, originalidade e variedade, complexidade, moralidade e qualidade. No que tange as reações afetivas em relação às séries, elas incluem a proximidade cultural, a ressonância pessoal, a elaboração cognitiva e a atitude geral. A metodologia consistiu em uma análise exaustiva de dez séries de televisão, cinco espanholas (Aída, Cuéntame, El internado, Águila Roja e Física o Química) e cinco americanas (CSI, Friends, House, Desperate Housewives e Lost) por meio de informações procedentes de uma pesquisa telefônica realizada com 1.000 pessoas. Os resultados indicam que as crenças influenciam a qualidade percebida. Os aspectos mais relevantes são os diálogos, as tramas, os atores e os personagens. Em relação às reações afetivas, os três elementos considerados (proximidade cultural, ressonância pessoal e elaboração cognitiva) estão apenas relacionados à atitude geral ou preferência pela série. As conclusões mostram que a qualidade percebida é determinada pela combinação dos diferentes fatores considerados e que não há uma configuração única que dê origem a uma percepção positiva de qualidade. A contribuição original do artigo para a literatura está na apresentação e aplicação de um modelo teórico que permite determinar detalhadamente as crenças e atitudes dos telespectadores em relação às séries de ficção televisiva.

\section{Palavras-chave (fonte: tesauro da Unesco)}

Televisão; ficção; crença; reação do público; reação emocional; série norte-americana; série espanhola. 


\section{Introducción}

Las cadenas de televisión han ido incorporando las series de ficción a sus parrillas de programación con la intención de atraer audiencia (HernándezGarcía, Ruiz-Muñoz y Simelio-Solà, 2013). En España, las seis principales cadenas generalistas dedican a la ficción desde un mínimo del 9,9\% del tiempo de emisión a un máximo del 30,7 \%. Así, la cadena que más tiempo de su programación dedica a contenido de ficción es Cuatro (30,7 \% del tiempo de emisión), seguida de Antena 3 (28,2 \%), La1 (19,0\%), La Sexta $(14,7 \%)$ y La2 y Tele 5 (ambas con un 9,9\%) (Kantar Media, 2013). Aunque a lo largo de los años se ha producido una mayor atracción de la audiencia por este tipo de contenidos (García de Castro, 2002; López, González y Medina, 2012), se constata, sin embargo, que existe un elevado porcentaje de fracasos entre los nuevos proyectos de series estrenadas, especialmente entre las españolas (García de Castro, 2008), en comparación con las norteamericanas (De Bens y De Smaele, 2001).

Dado que los costes de producción de las series de ficción son muy elevados, es importante analizar los factores que influyen en que la serie guste o no a los espectadores. Identificar con mayor precisión y conocer en mayor profundidad estos factores, estudiando su influencia en la percepción de la serie por parte del espectador, puede ayudar a los creadores y productores de las series de ficción a perfeccionar sus esfuerzos de adaptación a los gustos y las preferencias del público objetivo (Simons, 2013). Una vez identificados estos factores, puede analizarse qué combinación de ellos predice un mayor o menor éxito respecto de la aceptación del producto por parte de la audiencia.

Los elementos que influyen en cómo los espectadores perciben los productos audiovisuales han sido analizados en la literatura (Diego, Etayo y Pardo, 2011), especialmente en el caso del cine (Igartúa y Páez, 1997; Igartúa y Múñiz, 2008; Igartúa, Acosta y Frutos, 2013). En este sentido, los estudios sobre recepción televisiva han logrado importantes avances en el entendimiento de los procesos mediante los cuales los espectadores reciben e interpretan el consumo de programas de televisión (Grandío, 2007a).En el caso español, aunque existen trabajos que han estudiado el conjunto de 
la población (Lazo y Grandío, 2013); Lacalle y Gómez, 2017), gran parte de los esfuerzos por analizar los procesos de recepción televisiva se han enfocado en los menores y jóvenes (Lacalle, 2012; Ugalde, Martínez-deMorentín y Medrano-Samaniego, 2017) y en los migrantes (Huertas, Reguero y Sagarzazu, 2010).

Aunque los diferentes estudios examinan distintos factores, consideramos que estos pueden clasificarse en dos grandes tipos diferenciados: las creencias y las reacciones afectivas. Las creencias se refieren a juicios subjetivos que la persona hace sobre los atributos de la serie, esto es, el análisis de los aspectos concretos. Las reacciones afectivas son de naturaleza completamente subjetiva, ya que están basadas en los sentimientos personales que genera un objeto (en este caso, la serie de ficción).

Así como las creencias representan la percepción cognitiva que una persona tiene sobre un objeto, es decir, representan juicios subjetivos sobre cómo son las cosas, a pesar de que la información que una persona tenga sea objetiva (Petty y Cacioppo, 1996), las reacciones emocionales hacen referencia a evaluaciones positivas o negativas derivadas de las emociones y los sentimientos provocados por la serie. De esta forma, como muestran Fishbein y Ajzen (1975), la estructura de las creencias proporciona la base cognitiva de la reacción afectiva, es decir, la reacción emocional hacia la serie se basa en las creencias que se tengan sobre ella.

En este trabajo, se ofrece un modelo integrado de las creencias y reacciones emocionales de los telespectadores respecto de varias series de televisión. Por una parte, se identifican aspectos objetivos que los telespectadores pueden valorar de diferentes maneras. Concretamente, los atributos que se han analizado para las series elegidas en el estudio son los diálogos, las tramas, los actores y los personajes. Además, se analiza cómo se valoran otros factores de carácter objetivo como la originalidad y la variedad, la complejidad de la serie, su moralidad y su calidad. Por otra parte, se estudian diferentes reacciones afectivas en las series objeto de estudio, identificando como aspectos subjetivos que los telespectadores valoran de diferentes maneras la cercanía cultural, la resonancia, la elaboración cognitiva y la acti- 
tud general hacia la serie. La cercanía cultural es la consideración de que las situaciones que se presentan en la serie o película son cercanas o no al espectador. Se da esta cercanía cuando las situaciones, los acontecimientos y las personajes que se muestran en la serie se consideran como próximos o lejanos a la propia realidad del espectador (Larsen y Laszlo, 1990). La resonancia personal se refiere a los recuerdos de la propia vida que aparecen tras el visionado de la serie (Vorderer, Klimmt y Ritterfeld, 2004): es la denominada memoria emocional (Oatley, 1999). La serie hace surgir recuerdos personales que hacen que el espectador se implique en el relato. La elaboración cognitiva recoge el proceso por el cual la recepción de la serie desencadena una reflexión sobre las situaciones que en ella se plantean, es decir, si se realiza un proceso de reflexión sobre los temas tratados en la serie (Liebes y Katz, 1986; Vorderer, 1993). La valoración global estudia cuál es la actitud general a la serie, es decir, si el espectador tiene una buena opinión sobre ella, si disfruta con su visionado y si le gusta. Por tanto, la elección de los diferentes aspectos relativos a las reacciones afectivas es consistente con el hecho de que el proceso de recepción televisiva no se circunscribe al momento concreto en que el espectador ve la serie, sino que la interacción es más dilatada en el tiempo (Lazo, 2008; Fabbro y SánchezLabella, 2016). Así, se incluyen elementos como la resonancia, referidos al pasado, o la elaboración cognitiva, posterior al momento de visionado.

El objetivo de este trabajo es analizar todas estas dimensiones para el caso concreto de diez series de ficción de éxito emitidas en España, cinco de ellas españolas y cinco norteamericanas. Se trata de investigar cómo los aspectos mencionados son valorados para cada una de las series consideradas con el fin de complementar la evidencia empírica procedente de otros estudios realizados.

\section{Material y métodos}

Para la realización del estudio, se eligieron diez series de televisión, cinco de ellas españolas y cinco norteamericanas. El principal criterio de elección fueron sus altos índices de audiencia y su emisión en varias temporadas, lo que facilita la familiaridad del espectador con ellas y el índice de recuerdo. En la tabla 1, se presentan los datos de cada una de las series. Como puede 
verse, en las cinco series norteamericanas, figura la cadena en la que fueron emitidas originalmente, y entre paréntesis, la cadena de televisión española en la que fueron programadas. El dato de temporadas de emisión muestra cómo todas ellas se han emitido a lo largo de varias temporadas, por lo que la probabilidad de exposición de los espectadores ha sido alta.

\section{Tabla 1. Características de las series de televisión}

\begin{tabular}{|c|c|c|c|c|c|}
\hline Series & Nacionalidad & Producción & Cadena & Género & $\begin{array}{c}\text { Temporadas de } \\
\text { emisión }\end{array}$ \\
\hline Aída & Española & Globomedia & Telecinco & Humor & De 2005 a 2014 \\
\hline Cuéntame & Española & Grupo Ganga & La 1 & Drama & $\begin{array}{c}\text { De 2001 a la } \\
\text { actualidad }\end{array}$ \\
\hline El internado & Española & Globomedia & Antena 3 & Drama & De 2007 a 2010 \\
\hline Águila Roja & Española & Globomedia & La 1 & Aventuras & De 2009 a 2014 \\
\hline Física o Química & Española & Ida y Vuelta & Antena 3 & Drama-comedia & De 2008 a 2011 \\
\hline CSI & Norteamericana & $\begin{array}{c}\text { Jerry Bruckheimer } \\
\text { Television }\end{array}$ & $\begin{array}{c}\text { CBS } \\
\text { (Tele 5) }\end{array}$ & Policiaco & De 2000 a 2014 \\
\hline Friends & Norteamericana & $\begin{array}{c}\text { Bright, Kauffman y } \\
\text { Crane }\end{array}$ & $\begin{array}{c}\text { NBC } \\
\text { (Canal + })\end{array}$ & $\begin{array}{c}\text { Comedia de } \\
\text { situación }\end{array}$ & De 1994 a 2004 \\
\hline House & Norteamericana & David Shore & $\begin{array}{c}\text { FOX } \\
\text { (Cuatro })\end{array}$ & Drama médico & De 2004 a 2012 \\
\hline $\begin{array}{c}\text { Mujeres } \\
\text { desesperadas }\end{array}$ & Norteamericana & $\begin{array}{c}\text { ABC y Cherry } \\
\text { Productions }\end{array}$ & $\begin{array}{c}\text { ABC } \\
\text { (TVE) }\end{array}$ & $\begin{array}{c}\text { Comedia } \\
\text { dramática }\end{array}$ & De 2004 a 2012 \\
\hline $\begin{array}{c}\text { Perdidos } \\
\text { Abrams }\end{array}$ & Norteamericana & $\begin{array}{c}\text { ABC (TVE } \\
\text { y Cuatro }\end{array}$ & Misterio & De 2004 a 2010 \\
\hline
\end{tabular}

Fuente: elaboración propia.

Se eligieron estas series por ser muy conocidas por la mayoría de los espectadores, lo que facilitaba una correcta evaluación de los elementos que se le planteaban. Los datos se obtuvieron mediante la realización de una encuesta a 1000 personas. Esta se realizó por teléfono en junio de 2012 con cuotas de sexo y edad.

De las 1000 personas encuestadas, 479 eran hombres y 521 mujeres. Por edades, 134 personas tenían entre 14 y 24 años ( 66 hombres y $68 \mathrm{mu}$ jeres), 365 tenían entre 25 y 44 años ( 182 hombres y 183 mujeres), 301 personas eran de edades entre 45 y 65 años ( 144 hombres y 157 mujeres) y 200 personas eran mayores de 65 años ( 87 hombres y 113 mujeres). 
En primer lugar, el encuestado tenía que valorar cuánto le gustan las series españolas y las norteamericanas (de 0 a nada a 10 a muchísimo) y posteriormente se preguntaba por cuánto gustaban las diez series elegidas. En segundo lugar, se pedía al encuestado que valorara diversos aspectos (diálogos, tramas, actores, personajes, originalidad, variedad, calidad, etc.) sobre una serie concreta elegida de entre las conocidas por él.

\section{Análisis y resultados}

\section{Creencias sobre series de televisión}

En este apartado, se estudian las creencias de los telespectadores sobre las distintas series de televisión propuestas. A partir de la información incluida en la tabla 2, se examina la consideración que los telespectadores realizan de los diferentes aspectos que constituyen sus creencias en relación con las series. Ello nos va a permitir conocer la valoración que hacen de los diferentes elementos y evaluar cuáles de ellos cuentan con una mayor aceptación entre la audiencia.

\section{Diálogos}

En primer lugar, se analizan las creencias sobre los diálogos que mantienen los personajes de las series. Para ello, se formularon tres preguntas que tratan de recoger en una escala de 0 a 10 la percepción de los espectadores sobre los siguientes aspectos concretos: si las conversaciones entre los protagonistas son muy interesantes, si los diálogos son muy inteligentes y, finalmente, si los diálogos están muy trabajados.

Como puede observarse en la tabla 1, existen diferencias significativas en la consideración de los diálogos de las series estudiadas. Aunque es un aspecto bien valorado en general en las series examinadas (la media es de 6,39), las serie con mejores diálogos es House seguida de Águila Roja. De entre las 10 series analizadas, las que presentan una menor valoración en sus diálogos son Física o Química y Mujeres desesperadas.

\section{Tramas}

Para la valoración de esta dimensión, se establecen dos ítems, relativos a diversos aspectos relacionados con las tramas que acontecen en la serie: "La 
trama es tan buena que engancha rápidamente" y "Las historias están bien construidas". Ambos ítems obtienen una puntuación media de 6,8, lo cual nos permite afirmar que las historias de las series tienen una capacidad intermedia para conectar con el público y hacerle ver la serie semana tras semana. La puntuación más alta obtenida para los aspectos referidos a la trama la obtienen Perdidos y Águila Roja y las series cuyas tramas son peor valoradas son Mujeres desesperadas y Física o Química.

\section{Actores}

Para valorar el elenco de actores que participan en la serie, se utiliza la información procedente de dos preguntas. La primera es si interpretan bien su papel en la serie y la segunda si se ajustan bien a sus personajes. Los promedios de las respuestas obtenidos en estos dos ítems son 7,7 para la primera pregunta, y un 7,75 en su grado de ajuste a los personajes. Esto indica que los espectadores creen que los actores están muy bien elegidos para el papel que representan y que lo interpretan bien. La media de los dos ítems es de 7,73 , por lo cual puede considerarse un aspecto que está positivamente valorado por el público, por encima de los diálogos y las tramas. La serie cuyos actores son mejor valorados es Aída, seguida de Águila Roja, mientras que los peor valorados son los actores de Física o Química y Mujeres desesperadas.

\section{Personajes}

Para valorar las creencias respecto de los personajes de la serie, se plantean nuevamente dos preguntas. La primera de ellas trata de desentrañar si los personajes resultan creíbles o no. La puntuación media de las respuestas es de 6,95. La segunda pregunta, que examina si los personajes son percibidos como interesantes, ofrece una puntuación más alta, de 7,5. La media de los dos ítems es de 7,23, lo cual nos indica que se valora mejor a los actores de las series que a los personajes que representan. Los personajes mejor construidos son los de Águila Roja y Cuéntame; y los peor valorados, los de Perdidos y Mujeres desesperadas.

\section{Originalidad y variedad}

Para la evaluación de la serie, no solo en sí misma, sino en comparación con otras series de ficción, se examina la dimensión de originalidad y no repe- 
titividad. Para determinar la valoración de los espectadores sobre la originalidad, se preguntaron tres cuestiones. La primera, si se considera que la serie es muy diferente de otras, y la segunda si es original. Se preguntaba también si la serie es repetitiva. En la primera cuestión analizada, la puntuación media obtenida es 6,48. La puntuación obtenida para la afirmación "Es una serie muy original" alcanza el 6,72, por lo cual puede decirse que los espectadores consideran las series propuestas como bastante originales. Para la afirmación "La serie no es nada repetitiva", la puntuación media en la muestra es de 5,69. Esto nos indica que los espectadores valoran positivamente la originalidad de las series, pero creen que hay cierta dosis de repetición en el transcurso de una misma serie. Las series valoradas como más originales y menos repetitivas son Perdidos y Cuéntame y las menos Física o Química y CSI.

\section{Complejidad}

Para la valoración de esta dimensión, se establecen tres ítems distintos, relativos a diversos aspectos relacionados con las tramas que acontecen en la serie. Con el primer ítem, se evalúa si los episodios de la serie resultan difíciles de seguir, de modo que la puntuación es sensiblemente baja: un 3,59. Esto apunta a que los espectadores no encuentran mucha dificultad en seguir cada episodio. Un resultado similar se obtiene para el segundo ítem, que se refiere al nivel de complicación de las historias que se relatan en las series. El 3,27 que se obtiene de media permite concluir que la audiencia no encuentra problemas especialmente importantes para seguir la serie.

El tercer ítem analizado, "Dentro de un mismo capítulo pasan cosas diferentes”, por el contrario, alcanza un valor medio sustancialmente más elevado que los ítems anteriores $(6,08)$, lo cual indica que los telespectadores creen que las series tienen un ritmo adecuado y que cada capítulo presenta variedad de contenidos. Sin embargo, hay diferencias significativas en este aspecto en las distintas series. Las valoradas por los espectadores como más complejas son Perdidos y El internado, y las menos complejas son Aida y Friends. 


\section{Moralidad}

Una dimensión importante en las creencias sobre una serie es si contiene contenidos o escenas desagradables para el espectador, o bien por cuestiones de moralidad, o bien de carácter estético. Para determinar este punto, se estudian tres cuestiones. La primera de ellas hace referencia a si el telespectador cree que en la serie ocurren cosas desagradables, que puedan disgustarle. La puntuación media alcanzada para las series propuestas es de 4,89. La segunda valoración es respecto de la presencia de contenidos violentos. En este caso, la puntuación es extremadamente baja $(3,73)$, por lo cual puede afirmarse que las series, en general, no son percibidas como violentas en sus contenidos por el público. La tercera y última pregunta hace referencia a la inmoralidad de los contenidos. Para este ítem, la puntuación es de 3,26, lo cual nos indica que los espectadores perciben que en las series hay pocos contenidos inmorales. Analizando las series de manera individual, encontramos algunas diferencias importantes entre unas series y otras. CSI es la serie en la que suceden más cosas desagradables y los contenidos son más violentos. Física o Química se considera la serie con contenidos más inmorales. La serie en la que los contenidos son menos desagradables, violentos e inmorales es Friends, seguida de Aída.

\section{Calidad}

La última dimensión que abordamos es la calidad percibida de la serie, que puede entenderse como el resumen y la consecuencia integrada del resto de creencias consideradas previamente. Si bien la calidad puede considerarse desde otras perspectivas más objetivas y técnicas, en la línea de lo que son los objetivos de la presente investigación, la calidad es evaluada de acuerdo con la percepción que se han formado los espectadores tras el visionado de los capítulos de la serie.

Para la medición de la calidad, se emplean tres ítems. La primera pregunta cuestiona la factura técnica de la serie. La respuesta media al ítem "Está muy bien hecha" alcanza una puntuación de 7,45, lo cual nos indica que los espectadores valoran favorablemente este aspecto. Para la segunda cuestión ("Es una serie de calidad"), la puntuación baja a 7,29. Aunque este es inferior al anterior, no obstante indica que los espectadores las consideran bue- 
nas series respecto de la calidad. La última de las cuestiones, planteada en términos más exigentes ("Es una serie excelente"), da lugar a una puntuación promedio de 7. Aunque todas las series propuestas tienen alta puntuación en calidad, las más valoradas en este aspecto son Águila Roja y Friends, y la considerada de menor calidad es Física o Química seguida de Mujeres desesperadas. En consecuencia, no se detecta que los televidentes españoles sitúen las series nacionales por debajo de las norteamericanas en cuanto a estándares de calidad. Este resultado difiere del señalado por los jóvenes participantes en el estudio de Lacalle (2012). No hay duda de que la diferente composición de la muestra puede desempeñar un papel importante en la diferencia entre estos resultados y los detectados en nuestro trabajo.

En la tabla 2, se analizan también si las diferencias entre las series al considerar las distintas dimensiones son estadísticamente significativas. Como puede verse, los resultados del análisis de la varianza indican que se encuentran diferencias significativas al $99 \%$ en las valoraciones de todos los ítems analizados. Las mayores diferencias, no obstante, se encuentran en los ítems que evalúan las dimensiones originalidad y variedad y, especialmente, en complejidad y moralidad. Las creencias de los espectadores es que estos aspectos difieren mucho de unas series a otras.

El análisis de las creencias de los espectadores sobre las series objeto de estudio apunta a que el éxito de los productos audiovisuales no está asociado individualmente a ninguna de las dimensiones tomadas en consideración. Sin embargo, sí que se observa que una alta puntuación en cada una de las dimensiones analizadas se traduce en una mayor percepción de calidad de la serie por parte de la audiencia. En este sentido, la alta valoración de diálogos, tramas, actores y personajes de series como Águila Roja hace que su percepción de calidad sea la más alta de entre todas las analizadas. En sentido contrario, los casos de Física o Química y Mujeres desesperadas, cuya puntuación en estas cuatro dimensiones es la más baja de las series consideradas, hace que su calidad sea percibida también como más baja. En cuanto a las características de la serie relacionadas con su originalidad, complejidad y moralidad, encontramos que Cuéntame y Perdidos, valoradas como las más originales, tienen también una alta puntuación en 
calidad. Sin embargo, House, CSI, Aída y El internado, que tienen una valoración media en calidad, puntúan de forma muy diferente en las distintas dimensiones. CSI se caracteriza por su baja originalidad y alta puntuación en violencia en sus contenidos. Aída es una serie que, si bien tiene actores considerados muy buenos, su nivel de complejidad e inmoralidad es muy bajo. Del mismo nivel de calidad que ambas se considera House, cuyo punto fuerte son los diálogos. El único punto en el que la serie El internado obtiene alta puntuación, su complejidad, hace que su nivel de calidad esté al nivel medio. La serie Friends, percibida como de muy alta calidad, se caracteriza por puntuaciones medias en casi todas las dimensiones consideradas. El secreto de su éxito puede venir explicado por su bajo nivel de complejidad e inmoralidad.

Así pues, una vez analizados los datos, puede concluirse que las altas puntuaciones en diálogos, tramas, actores y personajes se asocian a mayor calidad y las puntuaciones bajas en estas mismas variables implican menor valoración de la calidad. Los resultados similares en cuanto al papel determinante de los personajes en la valoración de los programas de ficción han sido indicados por Lacalle (2012).

\section{Tabla 2. Las creencias de los telespectadores sobre las series de televisión}

\begin{tabular}{|c|c|c|c|c|c|c|c|c|c|c|c|c|c|}
\hline 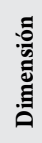 & 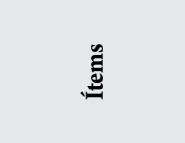 & स्: & 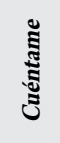 & 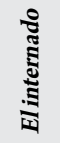 & 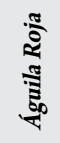 & 宽 & క్ & 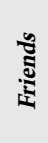 & : & 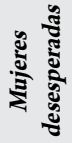 & & ङ્ّँ & F \\
\hline \multirow{3}{*}{ 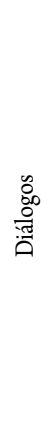 } & $\begin{array}{c}\text { Las } \\
\text { conversaciones de } \\
\text { los protagonistas } \\
\text { son muy } \\
\text { interesantes }\end{array}$ & 5,90 & 6,80 & 6,48 & 6,93 & 5,86 & 6,08 & 6,02 & 6,77 & 5,79 & 6,85 & 6,35 & $3,929^{* * *}$ \\
\hline & $\begin{array}{l}\text { Los diálogos son } \\
\text { muy inteligentes }\end{array}$ & 5,29 & 6,43 & 6,28 & 6,70 & 5,60 & 6,32 & 5,82 & 7,09 & 5,71 & 6,75 & 6,21 & $6,073^{* * *}$ \\
\hline & $\begin{array}{l}\text { Los diálogos están } \\
\text { muy trabajados }\end{array}$ & 6,53 & 6,63 & 6,72 & 7,08 & 5,97 & 6,49 & 6,51 & 7,26 & 5,94 & 6,97 & 6,62 & $3,549^{* * *}$ \\
\hline
\end{tabular}




\begin{tabular}{|c|c|c|c|c|c|c|c|c|c|c|c|c|c|}
\hline 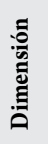 & 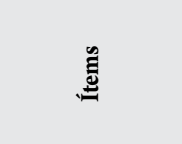 & ఫี & 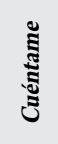 & 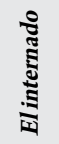 & 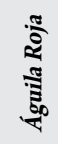 & 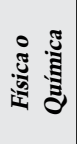 & ๘ & $\underset{\mathfrak{\Xi}}{\tilde{\Xi}}$ & $\stackrel{\mathscr{0}}{0}$ & 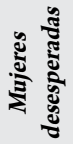 & $\frac{3}{0}$ & อี & F \\
\hline \multirow{2}{*}{ 莺 } & $\begin{array}{l}\text { Las historias } \\
\text { están muy bien } \\
\text { construidas }\end{array}$ & 6,40 & 7,02 & 7,24 & 7,25 & 6,42 & 6,91 & 6,62 & 6,75 & 6,17 & 7,31 & 6,81 & $3,252^{* * *}$ \\
\hline & $\begin{array}{l}\text { La trama es } \\
\text { tan buena } \\
\text { que engancha } \\
\text { rápidamente }\end{array}$ & 6,40 & 6,90 & 7,23 & 7,35 & 6,27 & 6,95 & 7,04 & 6,66 & 5,97 & 7,44 & 6,82 & $3,963^{* * *}$ \\
\hline \multirow{2}{*}{ 苋 } & $\begin{array}{l}\text { Los actores } \\
\text { interpretan bien } \\
\text { su papel }\end{array}$ & 8,14 & 7,85 & 7,70 & 8,05 & 7,23 & 7,32 & 7,77 & 8 & 7,22 & 7,74 & 7,70 & $3,349^{* * *}$ \\
\hline & $\begin{array}{l}\text { Los actores se } \\
\text { ajustan muy bien } \\
\text { a sus personajes }\end{array}$ & 8,14 & 7,92 & 7,66 & 8,09 & 7,26 & 7,54 & 7,91 & 7,89 & 7,28 & 7,82 & 7,75 & $2,757^{* * *}$ \\
\hline \multirow{2}{*}{ 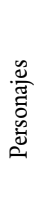 } & $\begin{array}{l}\text { Los personajes } \\
\text { me resultan muy } \\
\text { creíbles }\end{array}$ & 7,52 & 7,59 & 6,90 & 7,48 & 6,62 & 6,78 & 6,86 & 6,53 & 6,27 & 6,98 & 6,95 & $3,526^{* * *}$ \\
\hline & $\begin{array}{l}\text { Los personajes } \\
\text { son muy } \\
\text { interesantes }\end{array}$ & 7,10 & 7,07 & 7,20 & 7,71 & 6,78 & 6,78 & 6,86 & 7,09 & 7,06 & 6,34 & 7,50 & $2,589^{* * *}$ \\
\hline \multirow{3}{*}{ 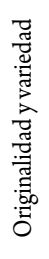 } & $\begin{array}{l}\text { Es muy diferente } \\
\text { de otras series }\end{array}$ & 6,37 & 6,91 & 6,76 & 6,61 & 5,58 & 6,20 & 5,91 & 6,90 & 6,18 & 7,44 & 6,48 & $4,932^{* * *}$ \\
\hline & $\begin{array}{c}\text { Es una serie muy } \\
\text { original }\end{array}$ & 6,83 & 6,89 & 6,82 & 6,95 & 5,60 & 6,37 & 6,79 & 6,99 & 6,37 & 7,57 & 6,72 & $4,388^{* * *}$ \\
\hline & $\begin{array}{l}\text { La serie no es } \\
\text { nada repetitiva }\end{array}$ & 5,87 & 6,18 & 6,30 & 6 & 5,20 & 5,09 & 5,48 & 5,30 & 5,39 & 6,14 & 5,69 & $2,936^{* * *}$ \\
\hline \multirow{3}{*}{ 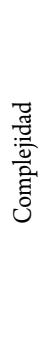 } & $\begin{array}{l}\text { Los episodios son } \\
\text { difíciles de seguir }\end{array}$ & 2,08 & 2,94 & 4,55 & 3,42 & 3,36 & 3,64 & 2,38 & 3,98 & 3,48 & 5,98 & 3,59 & $14,570^{* * *}$ \\
\hline & $\begin{array}{l}\text { Las historias son } \\
\text { complicadas de } \\
\text { entender }\end{array}$ & 1,84 & 2,50 & 4,44 & 2,92 & 2,87 & 3,57 & 2,04 & 4,01 & 2,93 & 5,71 & 3,27 & $17,925^{* * *}$ \\
\hline & $\begin{array}{l}\text { Dentro de un } \\
\text { mismo capítulo } \\
\text { pasan cosas } \\
\text { diferentes }\end{array}$ & 6,31 & 5,80 & 6,67 & 6,27 & 6,13 & 5,66 & 5,69 & 5,42 & 5,97 & 7,08 & 6,08 & $4,439^{* * *}$ \\
\hline \multirow{3}{*}{ 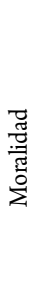 } & $\begin{array}{c}\text { En la serie } \\
\text { pasan cosas } \\
\text { desagradables }\end{array}$ & 2,56 & 4,47 & 6,12 & 5,02 & 5,16 & 7,03 & 2,06 & 6,21 & 4,18 & 5,95 & 4,89 & $37,875^{* * *}$ \\
\hline & $\begin{array}{l}\text { Tiene contenidos } \\
\text { violentos }\end{array}$ & 1,64 & 2,29 & 4,78 & 5,01 & 4,12 & 6,71 & 1,02 & 3,57 & 2,83 & 5,52 & 3,73 & $47,071^{* * *}$ \\
\hline & $\begin{array}{l}\text { Tiene contenidos } \\
\text { inmorales }\end{array}$ & 2,77 & 2,44 & 3,96 & 3,35 & 4,13 & 3,68 & 1,34 & 3,67 & 3,32 & 3,97 & 3,26 & $9,209^{* * *}$ \\
\hline
\end{tabular}




\begin{tabular}{|c|c|c|c|c|c|c|c|c|c|c|c|c|c|}
\hline 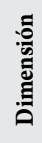 & $\stackrel{\mathscr{E}}{\Xi}$ & : & $\begin{array}{l}\text { ปี้ } \\
\text { ปี }\end{array}$ & 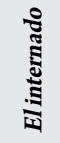 & 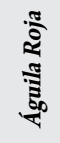 & 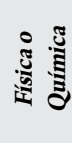 & క్ & : & : & 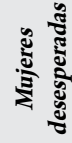 & & อٓํํ & $\mathbf{F}$ \\
\hline \multirow{3}{*}{ 胥 } & $\begin{array}{c}\text { Está muy bien } \\
\text { hecha }\end{array}$ & 7,57 & 7,62 & 7,28 & 7,94 & 6,71 & 7,38 & 7,76 & 7,68 & 7,08 & 7,46 & 7,45 & $2,824^{* * *}$ \\
\hline & $\begin{array}{l}\text { Es una serie de } \\
\text { calidad }\end{array}$ & 7,17 & 7,48 & 7,18 & 7,85 & 6,41 & 7,26 & 7,66 & 7,49 & 6,89 & 7,45 & 7,29 & $3,508^{* * *}$ \\
\hline & $\begin{array}{c}\text { Es una serie } \\
\text { excelente }\end{array}$ & 6,86 & 7,21 & 7,07 & 7,57 & 6,25 & 6,92 & 7,36 & 7,14 & 6,67 & 6,94 & 7 & $2,267^{* *}$ \\
\hline
\end{tabular}

Fuente: elaboración propia.

\section{Reacciones afectivas hacia las series de televisión}

En este apartado, se estudian las reacciones afectivas de los telespectadores hacia las series de televisión. La tabla 3 recoge los datos que nos permitirán examinar la consideración que los telespectadores realizan de los diferentes aspectos que constituyen sus reacciones afectivas en relación con las series. Se evalúa, además, cuáles de ellos cuentan con una mayor aceptación entre la audiencia.

\section{Cercanía cultural}

La cercanía cultural se ha medido con tres ítems: "Se reflejan estilos de vida similares al mío", "Se tratan situaciones parecidas a las que puedo encontrar en mi vida diaria" y "La serie está ambientada en un contexto muy parecido al mío". La media de estos tres ítems en el caso de las series elegidas es de 3,57, aunque existen importantes diferencias entre ellas. Las series que mayor cercanía tienen son Cuéntame y Física o Química, ambas españolas, lo que concuerda con el resultado obtenido en Lacalle (2012). Las que menos cercanía tienen son CSI y Águila Roja, lo cual significa que los espectadores perciben estas series como lejanas culturalmente a ellos. Especialmente baja es la puntuación del ítem "Está ambientada en un contexto muy parecido al mío”. En relación con este aspecto, debemos destacar la puntuación obtenida por Friends. A pesar de tratarse de una serie americana, los espectadores españoles perciben que es casi tan cercana culturalmente como una serie local tan costumbrista como Aída. Esto confirma para el conjunto de la población el resultado obtenido por Grandío (2007b) para una mues- 
tra fundamentalmente juvenil, justificado por la familiaridad de los espectadores con el género de la comedia de situación y el acostumbramiento a las series norteamericanas.

\section{Resonancia personal}

La resonancia personal se ha evaluado a través de los ítems "Me vienen recuerdos personales del pasado", "Revivo experiencias personales que me han sucedido", "Me vienen a la memoria recuerdos de mi vida”. Las dos series con mayor puntuación en resonancia cultural son Cuéntame y Física o Química. Las que menos resonancia provocan en los espectadores son CSI y Mujeres desesperadas.

\section{Elaboración cognitiva}

Para esta dimensión, se utilizaron cuatro ítems: "Reflexiona sobre el tema de que trata la serie", "Piensa sobre la situación y motivaciones de los personajes", "Intenta ver cómo el argumento de la serie se relaciona con otros temas que le interesan" y "Pretende sacar conclusiones sobre el tema central de la serie". Las series que propician más elaboración cognitiva son Física o Química y Perdidos. Por el contrario, CSI y Aída tienen unos valores muy bajos en esta dimensión.

La media de esta dimensión para todas las series es de 3,9. Es un valor más alto que el que se obtenía para las dimensiones de cercanía cultural y resonancia personal, lo cual indica que independiente del tema que plantee la serie y la relación personal del espectador con las situaciones planteadas, este reflexiona sobre lo que ve.

\section{Actitudes generales}

Para analizar la actitud general del espectador hacia la serie, se plantearon tres ítems: "Tengo una opinión muy positiva”, "Me lo paso bien viendo la serie" y "Es una serie que me gusta”. La puntuación media más alta se alcanzó para el ítem "Es una serie que me gusta", que obtuvo un valor medio de 7,49. La puntuación más baja fue para el ítem "Tengo una opinión muy positiva" $(7,4)$. La media para la valoración global de todas las series es de 7,45, lo cual significa que el público tiene una buena actitud hacia las 
series analizadas, le gustan estas series y disfruta con su visionado. Friends es la serie que obtiene una puntuación más elevada, mientras que Mujeres desesperadas es la que obtiene un menor valor medio.

\section{Tabla 3. Las actitudes de los telespectadores hacia las series de televisión}

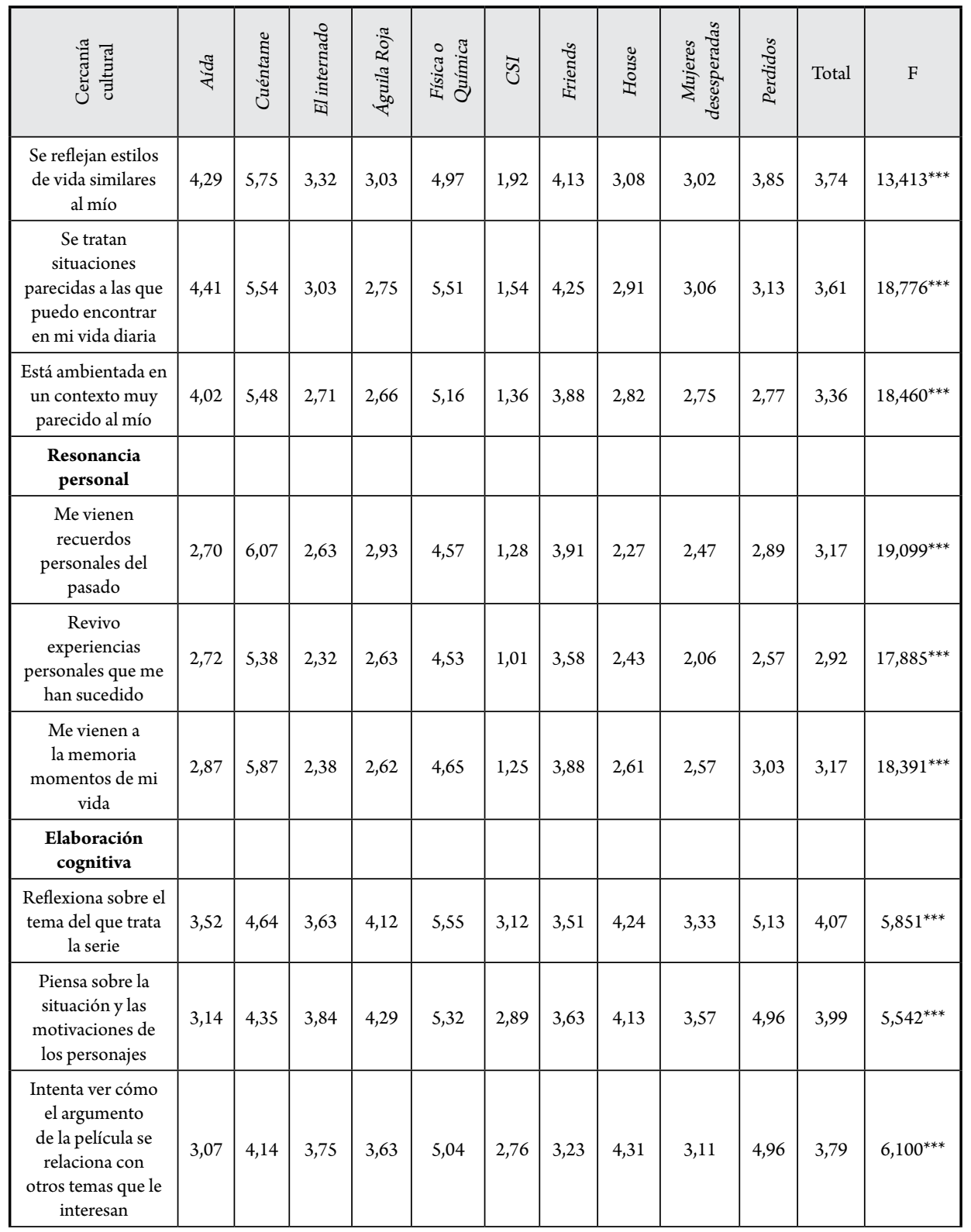




\begin{tabular}{|c|c|c|c|c|c|c|c|c|c|c|c|c|}
\hline 丞 营 & 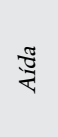 & 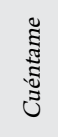 & 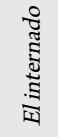 & 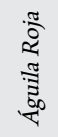 & 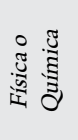 & $\bar{v}$ & :ี艹 & $\underset{\tilde{\Xi}}{\tilde{\Xi}}$ & 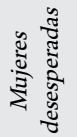 & 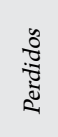 & Total & $\mathrm{F}$ \\
\hline $\begin{array}{c}\text { Pretende sacar } \\
\text { conclusiones sobre } \\
\text { el tema central de } \\
\text { la serie }\end{array}$ & 2,84 & 3,95 & 3,77 & 3,82 & 5 & 3,14 & 2,86 & 4,19 & 2,86 & 4,94 & 3,73 & $5,895^{* * *}$ \\
\hline \multicolumn{13}{|l|}{$\begin{array}{l}\text { Actitudes } \\
\text { generales }\end{array}$} \\
\hline $\begin{array}{l}\text { Tengo una opinión } \\
\text { muy positiva }\end{array}$ & 7,59 & 7,68 & 7,39 & 7,76 & 6,79 & 7,40 & 7,88 & 7,52 & 6,84 & 7,11 & 7,40 & $2,744^{* * *}$ \\
\hline Me lo paso bien & 7,70 & 7,47 & 7,29 & 8,02 & 7,12 & 7,35 & 8,02 & 7,60 & 6,84 & 7,27 & 7,47 & $2,648^{* * *}$ \\
\hline $\begin{array}{c}\text { Es una serie que } \\
\text { me gusta }\end{array}$ & 7,70 & 7,47 & 7,46 & 8,01 & 6,93 & 7,39 & 7,94 & 7,75 & 6,90 & 7,25 & 7,49 & $2,668^{* * *}$ \\
\hline
\end{tabular}

Fuente: elaboración propia.

\section{Conclusiones}

El objetivo de este trabajo ha sido ofrecer un modelo teórico que permita determinar de una forma pormenorizada las creencias y actitudes de los telespectadores respecto de las series de ficción televisiva. Se ha tratado de indagar cuáles son las creencias de los espectadores hacia las series de televisión mediante la valoración de distintos aspectos de esta: diálogos, tramas, actores, personajes, originalidad y variedad, complejidad, moralidad y calidad. Para analizar las reacciones afectivas hacia las series, se han estudiado varias de ellas: cercanía cultural, resonancia personal, elaboración cognitiva y actitud general hacia las series.

Este trabajo ha permitido realizar un análisis sistematizado de la opinión de los telespectadores respecto de las series más allá de las cifras de audiencia. Aunque estas son muy relevantes para acotar y medir el grado de aceptación de tales productos televisivos, cuentan con la limitación de ofrecer escasa información sobre los factores que explican su mayor o menor éxito. Para ello, se han analizado exhaustivamente diez series de televisión, cinco de ellas españolas (Aída, Cuéntame, El internado, Águila Roja y Física o Química) y cinco norteamericanas (CSI, Friends, House, Mujeres desesperadas y Perdidos). 
Los resultados indican que las creencias que los espectadores tienen sobre las series influyen en cómo valoran la calidad de estas. También se aprecia que no todas las variables tienen el mismo impacto en la evaluación final, destacando el peso en ella de los diálogos, las tramas, los actores y los personajes. A pesar de ello, el análisis de las creencias indica que no hay una única forma de conseguir que una serie de ficción sea valorada como de calidad por parte de los telespectadores. No hay combinaciones únicas de los elementos objetivos considerados que conduzcan a una valoración positiva por parte de la audiencia. Así, hemos encontrado series que sostienen estándares de calidad percibidos como altos por la audiencia basándose en una buena valoración de los elementos clave, como sería el caso de Águila Roja, mientras que en casos como el de Friends, la valoración global de su calidad es muy positiva sin destacar en ningún aspecto concreto.

Esta idea queda refrendada cuando examinamos la variabilidad entre series de las distintas variables de creencias. La variabilidad encontrada en las percepciones de la audiencia sobre los diferentes ingredientes objetivos es mucho mayor que la hallada para la valoración de la calidad. Esto indica que, aunque las series difieran en sus elementos, pueden alcanzar una mayor convergencia en sus niveles de calidad.

Aunque los distintos elementos objetivos definitorios de las series analizadas reciben una buena valoración por parte de los encuestados, hay uno de ellos con una puntuación inferior al resto. Se trata de los diálogos, lo que sugiere la conveniencia de prestar una mayor atención a este aspecto en la configuración de los diferentes capítulos de las series.

En relación con las reacciones afectivas de los telespectadores ante las series, los resultados obtenidos apuntan a que los tres elementos considerados (cercanía cultural, resonancia personal y elaboración cognitiva) no parecen estar muy relacionados positivamente con la actitud general o preferencia por la serie. Así, las dos series que más gustan a los participantes en nuestra encuesta (Águila Roja y Friends) no se encuentran entre las que más suscitan estas reacciones. Lo contrario le sucede a Fí- 
sica o Química: es más cercana culturalmente, provoca resonancias personales en la audiencia y genera reflexiones posteriores a su visionado, pero no parece ser muy del agrado del conjunto de la audiencia. Este resultado es consistente con la importancia atribuida al entretenimiento en la literatura sobre las gratificaciones derivadas de la ficción televisiva (Grandío, 2007b). De poco sirve que una serie genere reacciones afectivas si no logra el disfrute de aquellos que la están viendo. Este resultado hay que interpretarlo en el contexto de las variables elegidas en el trabajo para capturar las reacciones afectivas. Las tres dimensiones empleadas son susceptibles de ser ampliadas que incluyen aspectos directamente ligados con la evocación de emociones. Esto significa que no se puede deducir de esta investigación que los procesos afectivos no determinen en ninguna medida la preferencia de los espectadores por una serie. Nuestras conclusiones al respecto quedan circunscritas, por tanto, a las tres dimensiones aquí estudiadas.

Aunque se trata de dos factores conceptualmente diferentes, los resultados del trabajo también apuntan a que existe una estrecha relación entre el gusto por una serie y su calidad percibida. En nuestro caso, se produce bastante coincidencia entre las series que se perciben como de mayor calidad y aquellas que gustan más a la audiencia. Una pauta similar tiene lugar cuando centramos la atención en las series menos preferidas por el público, que también son las que cuentan con una calidad percibida inferior. Este resultado, en consecuencia, apunta a la importancia de la calidad del producto de ficción a la hora de cumplir su función de satisfacer las demandas de entretenimiento de la audiencia.

Entre las posibles extensiones de este trabajo que hagan frente a sus limitaciones, podemos indicar la conveniencia de contar con una muestra más amplia sobre un abanico mayor de series que permite validar de una forma más satisfactoria las conclusiones aquí obtenidas. Además, los resultados alcanzados, especialmente en lo concerniente a las reacciones afectivas, sugieren la necesidad de incorporar variables adicionales en este ámbito que permitan comprender mejor los procesos que conducen a la preferencia de los telespectadores en relación con las series de ficción. 


\section{Referencias}

Bens, de E. y Smaele, H. de (2001). The inflow of American television fiction on European broadcasting channels revisited. European Journal of Communication, 16(1), 51-76. DOI: $10.1177 / 0267323101016001003$

Diego, P., Etayo, C. y Pardo, A. (2011). La percepción sobre la calidad de las series televisivas en España: contraste entre el público y los profesionales. Zer: Revista de Estudios de Comunicación, 16(31), 6988. http://www.ehu.eus/ojs/index.php/Zer/article/view/4825

Fabbro, G. y Sánchez-Labella, I. (2016). Infancia, dibujos animados y televisión pública: la difusión de valores y contravalores en la producción española y argentina. Revista Mediterránea de Comunicación, 7(1), 11-29. DOI: 10.14198/MEDCOM2016.7.1.1

Fishbein, M. y Ajzen, I. (1975). Attitude, intention and behavior: An introduction to theory and research. Reading, EE. UU.: Addison-Wesley.

García de Castro, M. (2002). La ficción televisiva popular: una evolución de las series de televisión españolas. Barcelona, España: Gedisa.

García de Castro, M. (2008). Los movimientos de renovación en las series televisivas españolas. Comunicar, 15(30), 147-153. DOI: 10.3916/ c30-2008-02-008

Grandío, M. del M. (2007a). Recepción de la ficción televisiva norteamericana en España: el caso de Friends. Revista da Associacao Nacional dos Programas de Pos-Graduacao em Comunicacao, http://www.ecompos.org.br/e-compos/article/download/186/187

Grandío, M. del M. (2007b). Reflexiones sobre el estudio de las audiencias en España. Sphera Pública, número especial, 155-172. 
Hernández-García, P., Ruiz-Muñoz, M. J. y Simelio-Solà, N. (2013). Propuesta metodológica para el análisis de la ficción televisiva 2.0. Palabra Clave, 16(2), 449-469. DOI: 10.5294/pacla.2013.16.2.7

Huertas, A., Reguero, N. y Sagarzazu, I. (2010). Integración social y consumo mediático y cultural de los migrantes magrebíes en Cataluña. Zer: Revista de Estudios de Comunicación, 15(29), 213-233. http:// www.ehu.eus/ojs/index.php/Zer/article/view/1654

Igartua, J. J., Acosta, T. y Frutos, F. J. (2013). Recepción e impacto del drama cinematográfico: el papel de la identificación con los personajes y la empatía. Global Media Journal México, 6(11), 1-18. https:// journals.tdl.org/gmjei/index.php/GMJ_EI/article/view/75

Igartua, J. J. y Múñiz, C. (2008). Identificación con los personajes y disfrute ante largometrajes de ficción: una investigación empírica. Comunicación y Sociedad, 21(1), 25-52.https://www.unav.es/fcom/ communication-society/es/articulo.php?art_id=40

Igartua, J. J. y Páez, D. (1997). El cine sobre la guerra civil española: una investigación sobre su impacto en creencias y actitudes. Boletín de Psicología, 57, 7-39.

Kantar Media (2013). Anuario de Audiencia de Televisión 2013. Madrid, España: Kantar.

Lacalle Zalduendo, C. (2012). Género y edad en la recepción de la ficción televisiva. Comunicar, 20(39), 111-118. DOI: 10.3916/C392012-03-01

Lacalle Zalduendo, C. y Gómez Morales, B. (2017). La recepción televisiva española en la era multipantalla. Comunicación y Sociedad, 30, 197-216. DOI: 10.1080/01463373.201 
Larsen, S. F. y László, J. (1990). Cultural-historical knowledge and personal experience in appreciation of literature. European Journal of Social Psychology, 20(5), 425-440. DOI: 10.1002/ejsp.2420200505

Lazo, C. M. (2008). El proceso de recepción televisiva como interacción de contextos. Comunicar, 16(31), 35-40. DOI: 10.3916/c31-200801-004

Lazo, C. M. y Grandío, M. del M. (2013). Análisis de la competencia audiovisual de la ciudadanía española en la dimensión de recepción y audiencia. Communication \& Society, 26(2), 114-130. https://www.unav. es/fcom/communication-society/es/resumen.php?art_id $=450$

Liebes, T. y Katz, E. (1986). Patterns of involvement in television fiction: A comparative analysis. European Journal of Communication, 1(2), 151-171. DOI: 10.1177/0267323186001002004

López Vidales, N., González Aldea, P. y Medina de la Viña, E. (2012). Jóvenes y televisión en 2010: un cambio de hábitos. Zer: Revista de Estudios de Comunicación, 16(30), 97-113. http://www.ehu.eus/ ojs/index.php/Zer/article/view/4793/4659

Oatley, K. (1999). Why fiction may be twice as true as fact: Fiction as cognitive and emotional simulation. Review of General Psychology, 3(2), 101-117. DOI: 10.1037/1089-2680.3.2.101

Petty, R. E. y Cacioppo, J. T. (1996). Attitudes and persuasion: Classic and contemporary approaches. Boulder, EE. UU.: Westview Press.

Simons, N. (2013). Watching TV fiction in the age of digitization: A study into the viewing practices of engaged TV fiction viewers. International Journal of Digital Television, 4(2), 177-191. DOI: 10.1386/ jdtv.4.2.177_1 
Ugalde, L., Martínez-de-Morentín, J. I. y Medrano-Samaniego, C. (2017). Pautas de consumo televisivo en adolescentes de la era digital: un estudio transcultural. Comunicar, 25(50), 67-76. DOI: 10.3916/ C50-2017-06

Vorderer, P. (1993). Audience involvement and program loyalty. Poetics, 22(1-2), 89-98. DOI: 10.1016/0304-422X(93)90022-9

Vorderer, P., Klimmt, C. y Ritterfeld, U. (2004). Enjoyment: At the heart of media entertainment. Communication Theory, 14(4), 388-408. DOI: $10.1111 /$ j.1468-2885.2004.tb00321.x 